\title{
Still tilting at windmills
}

\section{Commentary on ... The myth of mental illness ${ }^{\dagger}$}

\author{
Edward Shorter ${ }^{1}$
}

The Psychiatrist (2011), 35, 183-184, doi: 10.1192/pb.bp.111.034108

${ }^{1}$ University of Toronto, Canada

Correspondence c/o The Psychiatrist (pb@rcpsych.ac.uk)

First received 25 Jan 2011, accepted 11 Feb 2011
Summary Thomas Szasz's essay misses several key points about the undoubted changes that psychiatry has undergone since he wrote his original screed against the discipline in 1961. Szasz fails to recognise that the discipline today acknowledges a neurological basis for much psychiatric illness. Thus, his fulminations against psychiatry for treating 'mental illness' is off-base. Szasz's original diatribe was heavily against psychoanalysis. Yet today Freud's doctrines can scarcely be said to play even a marginal role in psychiatry, and it is absurd to keep levelling the same old charges of 50 years ago. One has the feeling of looking at one of the last veterans of the Esperanto movement in confronting Szasz: lunacy at the time, bizarrely outdated today.

Declaration of interest None.
Just as Thomas Szasz's book The Myth of Mental Illness was an interesting mixture of bombast and insight when it appeared in 1961, so is his current essay ${ }^{1}$ an update on the bankruptcy of his basic views while reminding us that there are today some real problems with psychiatric diagnosis.

We will let the book lie. It was picked up by an antipsychiatry movement desperately seeking authorities with which to destroy the claim of psychiatry to be a medical specialty. Szasz, along with Ronald Laing, David Cooper, Michel Foucault and others, became celebrated as pathfinders of the view that schizophrenia was 'interesting' rather than tragic, and that if you were despairing and hopeless, then you should jolly well get your act together. In the wake of these fraudulent notions, many individuals neglected to seek help when psychiatry could well have rescued them from their melancholia and anhedonia. Many died by suicide.

This is so ironic. If you ask the producers of the movie One Flew Over the Cuckoo's Nest how many suicides they are responsible for, they would be nonplussed, even though the answer is many. If you ask the anti-psychiatry gurus how many suicides their storming against neuroscience has caused, they would be at a loss - and respond perhaps with a gibe against Prozac. But the answer is many. Books such as Szasz's delegitimised psychiatry in the eyes of much of the population, and drove desperately ill individuals away from such treatments as electroconvulsive therapy that could have been life saving.

'See special article, pp. 179-182, this issue.

\section{The wind of change}

Fast forward 50 years. Again, in Szasz's current essay we have the same mixture of cockeyed belligerence combined with the occasional insight. Szasz stamps his foot! There is no such thing as psychiatric illness because - ever the pathologist speaking - there are no characteristic brain lesions. Wait a minute. We now know several things about the neuropsychiatry of illness that we did not know in the early 1960s. Several psychiatric disorders do indeed have a brain basis. Melancholic depression may not be caused by a dysregulation of the hypothalamic-pituitary-adrenal (HPA) axis but HPA dysregulation reliably accompanies melancholia. And we know that because these individuals have high levels of serum cortisol, a positive dexamethasone suppression test, and a shortened rapid eye movement sleep latency. ${ }^{2}$ We did not know that in the early 1960s, when psychoanalysis ruled the roost. In those days, it did not even occur to most clinicians to ask about the biological side of illness.

There have been other biological advances since Szasz first wrote. In the early 1960s we knew about the role of panicogens in triggering panic disorder, obvious evidence of organicity. But we did not make very much of it because the scholars involved with this kind of research, such as Mandel Cohen at Harvard, ${ }^{3}$ were marginal to psychiatry - then dominated in the USA by such analytic big domes as Elvin Semrad at the Massachusetts Mental Health Center.

We have known since the 1930s of the immediate and positive response of catatonia to barbiturates; Gregory Fricchione and colleagues ${ }^{4}$ nailed the organicity of catatonia down in 1983 by reporting the strongly positive response of catatonia to benzodiazepines such as lorazepam. 
These are all solid biological findings in psychiatry, evidence of brain pathology, if one will. To insist that the major psychiatric illnesses do not have a biological basis - comparable to neurological illness - is to whistle in the wind. But this is what makes Szasz's cogitations today valueless - they do not recognise psychiatry's modern neuroscientific roots and continue to tilt at the same old 1950s' windmills. The main windmill Szasz tilted at was psychoanalysis, but today, to all intents and purposes, psychoanalysis is dead in psychiatry. And to continue to fulminate against it - as though the analysts' belief in 'intrapsychic conflict' represented the basis of psychiatric science today - is intellectually untenable and uninteresting.

\section{Politicisation of psychiatric diagnoses}

Yet Szasz does hit some nails squarely on the head, and he is among the few observers to have called attention to some unpleasant realities. One is that the official diagnostic classification of psychiatry, the Diagnostic and Statistical Manual (DSM) series of the American Psychiatric Association (APA), is indeed a political document. It is not a classification inspired by Washington DC 'inside-thebeltway' style politics. And when Szasz brandishes Bill Clinton at us in his essay, it is unconvincing. Yet the APA definitely has a politics of its own. The reality is that the DSM series, particularly the third edition of it that Robert Spitzer produced in 1980, was quite a political document. Spitzer has admitted as much. ${ }^{5}$ He said it was a 'consensus document', meaning the product of the give-and-take that characterises any consensus committee. However, we did not get the speed of light from a consensus committee, and for the APA to pretend that consensus politics has anything to do with science is simply disingenuous. So Szasz is right about that.

Psychiatric diagnosis is also political in that it reflects the larger culture and politics of the society within which it is imbedded. And the sexual disorders section of DSM, for example, is a crystal reflection of mainline Judeo-Christian morality. Ah yes, as Szasz observes, homosexuality is now drawn within the magic circle of approval. So we do indeed see politics at work.
Now, Szasz has one particular sleight of hand with which he has trumped his gainsayers over the years: 'If all the "conditions" now called "mental illnesses" proved to be brain diseases, there would be no need for the notion of mental illness and the term would become devoid of meaning.' Yes, that is exactly right. Psychiatry today increasingly avoids 'mental illness' because the term is a psychoanalytic hold-over suggesting that psychiatric illness is mainly psychogenic, thus an illness of the mind. But no serious neuroscientist believes this anymore. Increasingly, 'psychiatric disease' is preferred, suggesting brain illnesses as organic as Parkinson's disease. (The DSM term 'disorder' is a weasel word.) Indeed, there are a number of overlaps between non-motor forms of Parkinson's disease and depressive illness. ${ }^{6}$ 'Mental illness' is still used in public fundraising, in the view that people will find the term less terrifying than 'psychiatric disease'. But the trend in psychiatry today is towards the brain disease approach, and therewith Szasz would actually be obliged to say, 'OK, you guys win'. But will he?

\section{About the author}

Edward Shorter is Jason A. Hannah Professor of the History of Medicine, Professor of Psychiatry, Faculty of Medicine, University of Toronto, Toronto, Canada.

\section{References}

1 Szasz T. The myth of mental illness: 50 years later. Psychiatrist 2011; 35: 181-184.

2 Shorter E, Fink M. Endocrine Psychiatry: Solving the Riddle of Melancholia. Oxford University Press, 2010.

3 Cobb S, Cohen M. Experimental production during rebreathing of sighing respiration and symptoms resembling those in anxiety attacks in patients with anxiety neurosis. Am Soc Clin Invest 1940; 19: 789.

4 Fricchione GL, Cassem NH, Hooberman D, Hobson D. Intravenous lorazepam in neuroleptic-induced catatonia. J Clin Invest 1983; 3: 338-42.

5 Shorter E. Before Prozac: The Troubled History of Mood Disorders in Psychiatry. Oxford University Press, 2009.

6 P Barone. Neurotransmission in Parkinson's disease: beyond dopamine. Eur J Neurology 2010; 17: 364-76. 